\title{
Lactonase activity and status of paraoxonase 1 in Chinese women with polycystic ovarian syndrome
}

\author{
Yujin Zhang ${ }^{1}$, Hongwei Liu' ${ }^{1}$ Jin $\mathrm{He}^{2}$, Kelei $\mathrm{Xu}^{2}$, Huai Bai ${ }^{3}$, Ying Wang ${ }^{1}$, Feng Zhang ${ }^{1}$, \\ Jinxia Zhang ${ }^{3}$, Li Cheng ${ }^{2}$ and Ping Fan ${ }^{3}$ \\ ${ }^{1}$ Department of Obstetrics and Gynecology, West China Second University Hospital, ${ }^{2}$ West China School of Pharmacy \\ and ${ }^{3}$ Laboratory of Genetic Disease and Perinatal Medicine and Key Laboratory of Birth Defects and Related \\ Diseases of Women and Children of Ministry of Education, West China Second University Hospital, Sichuan \\ University, Chengdu, Sichuan 610041, People's Republic of China
}

\author{
Correspondence \\ should be addressed \\ to P Fan \\ Email \\ fanping15@scu.edu.cn
}

\begin{abstract}
Objective: To study the relationship between the lactonase activities and status of paraoxonase 1 (PON1) and its association with the PON1 genetic polymorphisms in women with polycystic ovarian syndrome (PCOS).

Design: A case-control study.

Methods: A total of 455 PCOS patients and 441 control women were included in this study. The lactonase activities and concentrations of PON1 were assayed using 5-thiobutyl butyrolactone (TBBL) and 7-O-diethylphosphoryl-3-cyano-4-methyl7-hydroxycoumarin (DEPCyMC) respectively. A normalized lactonase activity (NLA) was estimated based on the ratio of TBBLase:DEPCyMCase activity. The PON1 genotypes, serum malondialdehyde (MDA) levels and total antioxidant capacity were analyzed.

Results: The lactonase activities and levels of PON1 were higher in PCOS patients than in the control women. However, the NLA did not significantly differ between groups. The $-108 \mathrm{C} \rightarrow T$ variation of the PON1 gene showed decreased lactonase activities and levels of PON1 in a genotype-dependent manner (CC $>C T>T T)$; the $192 Q \rightarrow R$ variation of the $P O N 1$ gene showed increased PON1 lactonase activities and NLA; and the $55 L \rightarrow M$ variation of the PON1 gene showed decreased lactonase activities and levels of PON1 but an increased NLA. A multivariable regression analysis showed that the $-108 C / T$, $192 Q / R$, and 55L/M variations of the PON1 gene, serum apolipoprotein A1, and MDA levels were significant predictors of PON1 lactonase activity, PON1 level, and NLA.

Conclusions: The serum lactonase activities and concentrations of PON1 are increased in PCOS patients. The increased oxidative stress and the $-108 \mathrm{C} / \mathrm{T}, 192 \mathrm{Q} / \mathrm{R}$, and $55 \mathrm{~L} / \mathrm{M}$ genetic polymorphisms of PON1 may be associated with these changes.

\section{Introduction}

Polycystic ovary syndrome (PCOS) is a heterogeneous endocrine metabolic disorder characterized by oligo- or anovulation (OA), biochemical or clinical hyperandrogenism (HA), and the presence of polycystic ovaries (PCO) (1). PCOS affects $6-15 \%$ of reproductive-age women $(2,3)$. PCOS is often associated with obesity (4), increased oxidative stress (5), systemic chronic inflammation (6), elevated prevalences of metabolic syndrome and type 2 diabetes (7), and potentially increased risks of atherosclerosis and cardiovascular disease $(8,9)$. The etiology of PCOS remains unclear, but studies have suggested that PCOS appears to have a complex, multifactorial etiology in which a variety of predisposing genes interact with environmental factors to produce the disease $(10,11)$.

Serum paraoxonase 1 (PON1) is a calcium-dependent multifunctional enzyme that is mainly expressed by the liver and circulates within HDL particles $(12,13)$.

Published by Bioscientifica Ltd. 
PON1 has paraoxonase (POase), arylesterase (AREase), lactonase, and Hcy-thiolactonase (HTase) activities $(13,14)$. Thus, it can not only detoxify several organophosphorus insecticides and nerve agents to protect against xenobiotic toxicity, but it can also inhibit LDL oxidation and increase macrophage-associated cholesterol efflux. It also possesses antioxidant, anti-inflammatory, and anti-atherogenic properties $(13,15,16,17)$. Recent studies have shown that the physiological roles of PON1 are related to its lactonase and HTase activities. PON1 can hydrolyze a wide range of lactones that are structurally similar to many oxidized mediators of polyunsaturated fatty acids $(13,18,19)$ and homocysteine thiolactone, which can increase the homocysteinylation of proteins and lead to protein inactivation and cell damage. Thus, PON1 plays beneficial roles in the prevention of atherosclerosis $(12,14,20)$.

Recently, new serum PON1 activity tests have been developed using 5-thiobutyl butyrolactone (TBBL) or 7-Odiethylphosphoryl 3-cyano 4-methyl 7-hydroxycoumarin (DEPCyMC) as substrates $(21,22)$. TBBL is a synthetic chromogenic lactone that resembles the most natural PON1 lactone substrates, thus allowing a specific evaluation of PON1 lactonase activity $(18,23)$. DEPCyMC is a chromogenic phosphotriester substrate that allows the total PON1 concentration to be estimated (21). The ratio of TBBL:DEPCyMC activity has been suggested to provide the so-called 'normalized lactonase activity (NLA)', which may reflect the level of PON1 lactonase catalytic stimulation by $\operatorname{HDL}(21,24)$.

The POase and/or AREase activities are reportedly lower $(25,26,27,28)$ or similar $(29,30)$ and the HTase activity is decreased (31) in PCOS patients compared with control women. However, the level, lactonase activity, and NLA of PON1 have not yet been assessed in PCOS patients. The aim of this study was to investigate these new PON1 activities and PON1 levels, and their association with PON1 genetic polymorphisms in PCOS patients.

\section{Subjects and methods}

\section{Subjects}

This is a case-control study. Women with or without PCOS between 17 and 40 years of age were randomly recruited from the Outpatient Clinic of Reproductive Endocrinology, West China Second University Hospital, Sichuan University from 2006 to 2013 as described before $(32,33)$. All participants gave their informed consent and the study was approved by the Institutional Review Board of the West China Second University Hospital.
PCOS was defined by the presence of two or more of the following features based on the revised 2003 Rotterdam diagnostic criteria (1): OA was assessed as oligomenorrhoea, i.e., less than eight cycles per year. HA was assessed as total testosterone (TT) levels above the 95th percentile of the levels $(2.60 \mathrm{nmol} / \mathrm{l})$ detected in a group of normal menstruating women with normal cycles and/or clinically by the presence of obvious acne (33) and/or hirsutism with a F-G score of more than $6(33,34,35)$. PCO was confirmed if 12 or more follicles in each ovary measured 2-9 $\mathrm{mm}$ in diameter and/or the ovarian volume was increased $(>10 \mathrm{ml})$ by ultrasonic examination with exclusion of other etiologies, such as congenital adrenal hyperplasia, androgen-secreting carcinomas, and Cushing's syndrome. All control women had regular menstrual cycles (between 21 and 35 days), exhibited normal circulating androgen levels, the absence of obvious acne or hirsutism on physical examination, and normal ovarian morphology as determined by ultrasound.

The subjects were excluded if they met one of the following criteria: i) clinically evident chronic or acute diseases, such as infection, tumors, thyroid dysfunction, cardiovascular diseases, endometriosis, hyperprolactinemia, hypogonadotropic hypogonadism, or premature ovarian failure; ii) pregnant or in the luteal phase based on progesterone measurement $(>9.54 \mathrm{nmol} / \mathrm{l})$; iii) taking medication known to affect the metabolism of carbohydrates, lipids, or hormones within 3 months before the study; iv) age <20 years; and v) smokers.

Clinical and anthropometrical variables, including the waist circumference (WC), hip circumference, waistto-hip ratio (WHR), BMI $\left(\mathrm{kg} / \mathrm{m}^{2}\right)$, systolic and diastolic blood pressure (SBP and DBP), and the degree of hirsutism and acne, were measured or assessed in all subjects. The ultrasound ovarian volume was also assessed using the formula for the volume of an ellipsoid (36): $0.523 \times$ length $\times$ width $\times$ thickness.

Blood samples were obtained in the morning after overnight fasting, placed on ice immediately, and centrifuged at $1500 \mathrm{~g}$ for $15 \mathrm{~min}$ at $4{ }^{\circ} \mathrm{C}$ within $2 \mathrm{~h}$. The serum and plasma samples were stored in 200-300 $\mu$ l aliquots at $-80{ }^{\circ} \mathrm{C}$ for later analysis, and blood cells in tubes containing EDTA were stored at $4{ }^{\circ} \mathrm{C}$.

\section{PON1 activity assays}

The substrates TBBL and DEPCyMC were synthesized as shown in the Supplemental data, see section on supplementary data given at the end of this article, according to previous reports $(21,22)$ with some modifications. 
The PON1 lactonase activity was determined as previously described $(22,24)$. A $100 \mathrm{mM}$ stock of 5,5'dithio-bis-2-nitrobenzoic acid (DTNB) was prepared in DMSO. The serum was diluted 400-fold in a sample buffer (50 mM Tris pH 8.0, $1 \mathrm{mM} \mathrm{CaCl}_{2}$, and $1 \mathrm{mM} \mathrm{DTNB}$ ). TBBL was diluted 500 -fold from a $500 \mathrm{mM}$ stock (in acetonitrile) using substrate buffer (50 mM Tris $\mathrm{pH} 8.0,1 \mathrm{mM} \mathrm{CaCl}_{2}$, and $2 \%$ acetonitrile). The reaction was initiated by adding $100 \mu \mathrm{l}$ of TBBL $(1 \mathrm{mM})$ to $100 \mu \mathrm{l}$ diluted serum, and the kinetics were immediately measured using the Varioskan Flash Multimode Microplate Spectrophotometer (Thermo Scientific, Vantaa, Finland) by monitoring the absorbance at $412 \mathrm{~nm}$ for $5 \mathrm{~min}$ at $25^{\circ} \mathrm{C}(\varepsilon=7000 \mathrm{OD} / \mathrm{M})$. The rate of spontaneous hydrolysis of TBBL in the buffer was subtracted from all measurements. The activities are expressed as $\mathrm{U} / \mathrm{ml}$ ( 1 unit $=1 \mu \mathrm{mol}$ of TBBL hydrolysed/ min per $\mathrm{ml}$ of undiluted serum).

The serum PON1 levels were assessed by measuring the activity using DEPCyMC as a substrate (21). A $100 \mathrm{mM}$ stock of DEPCyMC was prepared in DMSO. The kinetics were measured using $20 \mu \mathrm{l}$ of serum and $180 \mu \mathrm{l}$ of assay buffer (50 mM bis-trispropane $\mathrm{pH}$ 9.0, $1 \mathrm{mM} \mathrm{CaCl}_{2}$, and $1 \mathrm{mM}$ DEPCyMC) by monitoring the absorbance at $400 \mathrm{~nm}$ for $5 \mathrm{~min}$ at $25^{\circ} \mathrm{C}(\varepsilon=22240 \mathrm{OD} / \mathrm{M})$. The rate of spontaneous hydrolysis of DEPCyMC in buffer was subtracted from all measurements. The activities are expressed as $\mathrm{mU} / \mathrm{ml}$ ( 1 milli unit $=1 \mathrm{nmol}$ of DEPCyMC hydrolysed/min per $\mathrm{ml}$ of undiluted serum).

The samples were plated in duplicate, and a pooled serum sample from healthy volunteers was measured on each plate as a quality control. The intra- and inter-assay coefficients of variation $(\mathrm{CV})$ for all measurements were $<5 \%$.

\section{Genotype analysis}

The genomic DNA was isolated from the peripheral blood leukocytes of subjects and the PON1 $-108 C / T, 192 Q / R$, and 55L/M genotypes were assessed by PCR amplification and restriction analysis as described previously $(34,37)$.

\section{Analysis of serum total antioxidant capacity and malondialdehyde levels as well as hormonal and metabolic profiles}

The levels of serum follicle-stimulating hormone (FSH), luteinizing hormone (LH), TT, estradiol, and progesterone as well as the concentrations of fasting plasma insulin (Ins) and glucose (Glu), total cholesterol (TC), HDL-cholesterol (HDL-C), LDL-cholesterol (LDL-C), triglyceride (TG), apolipoprotein A1 (apoA1) and apoB, homeostasis model insulin resistance index (HOMA-IR), and atherogenic index (AI) were measured or assessed as described before (33). The serum total antioxidant capacity (T-AOC) and malondialdehyde (MDA) levels were determined by spectrophotometry using T-AOC kits and micro-MDA kits (NanJing Jiancheng Bioengineering Institute, Nan Jing, China) respectively. The intra- and inter-assay CV for all measurements were $<5$ and $10 \%$ respectively.

\section{Statistical analyses}

The data are presented as the mean \pm s.D. Differences in variables between the PCOS and control groups were evaluated with an independent sample $t$-test, a MannWhitney $U$ test or an analysis of covariance (ANCOVA). A $\chi^{2}$ analysis was used to test deviations of the genotype distribution from the Hardy-Weinberg equilibrium and to determine allele or genotype frequencies between patients and controls. The effects of PCOS phenotypes or PON1 genotypes on the clinical and metabolic parameters were estimated with an ANOVA or ANCOVA. A Pearson's correlation was performed to define correlations between the PON1 lactonase activities and the PON1 levels. Multivariate stepwise regression analyses were used to assess the effect of other parameters, including the $-108 \mathrm{C} / \mathrm{T}, 192 \mathrm{Q} / \mathrm{R}$, and $55 \mathrm{M} / \mathrm{L}$ genotypes of PON1; PCOS; age; BMI; SBP; DBP; WC; F-G score; average ovarian volume; TT; FSH; $\mathrm{LH}$; the fasting insulin and glucose levels; and the TG, LDL-C, apoA1, apoB, MDA, and T-AOC levels on the PON1 lactonase activity, PON1 level, or NLA in all subjects. We excluded some parameters, such as the WHR, LH:FSH ratio, HOMA-IR, TC, HDL-C, AI, and TG:HDL-C ratio, from the regression models due to the presence of a co-linearity between these parameters and some of the independent variables. A value of $P<0.05$ was considered to be statistically significant. All statistical analyses were performed using the Statistical Program for Social Sciences (SPSS) 13.0 for Windows.

\section{Results}

\section{Selection of subjects}

Women with or without PCOS $(n=1778)$ were randomly recruited in the same manner and during the same period. Of these subjects, 755 women met the revised 2003 Rotterdam diagnostic criteria for PCOS and 702 women met the control women's inclusion criteria. After excluding 
subjects meeting one or more of the exclusion criteria and those missing data for PON1 activities or the PON1 genetic polymorphisms, 455 PCOS patients and 441 control women were finally included in this study.

The controls consisted of: i) infertile women (59.9\%) due to Fallopian obstruction $(28.8 \%)$ or male factor infertility; ii) women presenting for preconception counseling (35.8\%); and iii) healthy volunteers, doctors, and nurses $(4.3 \%)$.

\section{Clinical and biochemical characteristics of the study population}

As given in Table 1, the BMI, WC, WHR, F-G score, DBP, and average ovarian volume were significantly higher and the age was significantly lower in the PCOS group than in the control group.

The TT and LH levels, LH:FSH ratio, fasting insulin, HOMA-IR, TC, TG, LDL-C and apoB levels, AI, TG:HDL-C

Table 1 Clinical and biochemical characteristics of the subjects. Values are presented as the mean \pm s.D.

\begin{tabular}{l}
\hline \\
Clinical characteristics \\
Age (years) \\
BMI (kg/m²) \\
Waist circumference (cm) \\
Waist-to-hip ratio (WHR) \\
Ferriman-Gallwey score \\
SBP (mmHg) \\
DBP (mmHg) \\
Ovarian volume (ml) \\
Hormonal levels \\
TT (nmol/l) \\
LH (IU/l) \\
FSH (IU/l) \\
LH/FSH \\
Metabolic profiles \\
Fasting Ins (pmol/l) \\
Fasting Glu (mmol/l) \\
HOMA-IR \\
TG (mmol/l) \\
TC (mmol/l) \\
HDL-C (mmol/l) \\
LDL-C (mmol/l) \\
Al \\
TG/HDL-C \\
ApoA1 (g/l) \\
ApoB (g/l) \\
MDA (nmol/ml) \\
T-AOC (U/ml per min) \\
PON1 lactonase activity (U/ml) \\
PON1 level (mU/ml) \\
NLA \\
PON1 genetic polymorphisms \\
$-108 C / T, \%(n)$ \\
CC \\
CT \\
TT \\
Q2Q/R, \% ( $n$ ) \\
QR \\
$R R$ \\
$55 L / M, \% ~(n)$ \\
LL \\
LM
\end{tabular}

Controls $(n=441)$

$28.11 \pm 4.08$
$21.01 \pm 2.74$
$73.11 \pm 7.95$
$0.81 \pm 0.06$
$0.21 \pm 0.67$
$113.21 \pm 11.70$
$73.52 \pm 8.71$
$7.81 \pm 2.71$

$1.57 \pm 1.05$
$8.50 \pm 10.98$
$6.57 \pm 2.96$
$1.31 \pm 1.35$

$65.06 \pm 35.14$
$5.29 \pm 0.46$
$2.25 \pm 1.36$
$1.01 \pm 0.54$
$4.24 \pm 0.70$
$1.51 \pm 0.32$
$2.33 \pm 0.61$
$1.90 \pm 0.67$
$0.74 \pm 0.63$
$1.43 \pm 0.19$
$0.75 \pm 0.16$
$3.60 \pm 1.20$
$14.97 \pm 2.80$
$9.43 \pm 1.62$
$44.23 \pm 6.43$
$213.01 \pm 16.79$

$30.4(134)$
$52.8(233)$
$16.8(74)$

$14.5(64)$
$50.3(222)$
$35.1(155)$
$92.5(408)$
$7.5(33)$

\begin{tabular}{|c|c|}
\hline$P$ & $\boldsymbol{P}^{a}$ \\
\hline $\begin{array}{r}<0.001 \\
<0.001 \\
<0.001 \\
<0.001 \\
<0.001 \\
0.058 \\
0.003 \\
<0.001\end{array}$ & \\
\hline $\begin{array}{r}<0.001 \\
<0.001 \\
0.001 \\
<0.001\end{array}$ & $\begin{array}{r}<0.001 \\
<0.001 \\
0.066 \\
<0.001\end{array}$ \\
\hline $\begin{array}{r}<0.001 \\
<0.001 \\
<0.001 \\
<0.001 \\
0.001 \\
<0.001 \\
<0.001 \\
<0.001 \\
<0.001 \\
<0.001 \\
<0.001 \\
<0.001 \\
<0.001 \\
0.007 \\
0.007 \\
0.384\end{array}$ & $\begin{array}{r}<0.001 \\
0.398 \\
0.001 \\
<0.001 \\
<0.001 \\
0.046 \\
<0.001 \\
<0.001 \\
<0.001 \\
0.451 \\
<0.001 \\
<0.001 \\
0.003 \\
0.006 \\
0.004 \\
0.563\end{array}$ \\
\hline $0.017^{b}$ & \\
\hline $0.354^{b}$ & \\
\hline
\end{tabular}

$29.0(132)$

$50.3(229)$

$20.7(94)$

$11.0(50)$

44.8 (204)

44.2 (201)

94.1 (428)
$25.11 \pm 3.75$

$0.85+0.07$

$2.42 \pm 0.76$

$14.07+11.78$

$05.12 \pm 75.56$

$5.44 \pm 0.74$

$1.42+1.15$

$1.21 \pm 1.43$

$16.28+3.18$

$9.73 \pm 1.70$

$45.41 \pm 6.70$

$214.00 \pm 17.14$

$5.9(27)$
$5.97 \pm 2.36$

$\mathrm{Al}$, atherosclerosis index; apoA1, apolipoprotein $\mathrm{A1}$; apoB, apolipoprotein $\mathrm{B}$; DBP, diastolic blood pressure; $\mathrm{FSH}$, follicle-stimulating hormone; Glu, glucose; HDL-C, HDL-cholesterol; HOMA-IR, homeostasis model insulin resistance index; Ins, insulin; LDL-C, LDLcholesterol; LH, luteinizing hormone; MDA, malondialdehyde; NLA, normalized lactonase activity; PCOS, polycystic ovarian syndrome; SBP, systolic blood pressure; T-AOC, total antioxidant capacity; TC, total cholesterol; TG, triglyceride; TT, total testosterone. ${ }^{a}$ All comparisons of parameters were corrected for differences in age and BMI between the two groups. 
ratio, MDA concentrations, T-AOC, PON1 levels, and PON1 lactonase activities were significantly higher and the HDL-C levels were significantly lower in the PCOS patients than in the controls (Table 1).

The genotypic distributions of the PON1 $-108 \mathrm{C} / \mathrm{T}$, $192 Q / R$, and 55L/M gene sites were in Hardy-Weinberg equilibrium in the PCOS and control groups. No significant differences were found in the frequencies of the PON1 - 108C/T and 55L/M genotypes between the PCOS and control groups. However, PON1 192RR genotype was significantly more prevalent in the PCOS patients compared with the control women $(44.2 \%$ vs $35.1 \%$, $P=0.017)$.

\section{Lactonase activity and status of PON1 and oxidative stress parameters in different PCOS phenotypes}

We further analyzed the age- and BMI-adjusted level, lactonase activity and NLA of PON1, PON1 genetic polymorphisms, and oxidative stress parameters in control women and in patients with different key clinical phenotypes of PCOS: i) $\mathrm{HA}+\mathrm{OA}+\mathrm{PCO}$, ii) $\mathrm{HA}+\mathrm{OA}$, iii) $\mathrm{HA}+\mathrm{PCO}$, and iv) $\mathrm{OA}+\mathrm{PCO}$ (Table 2). Compared with the control subjects, each of the four PCOS subgroups had higher MDA levels; the $\mathrm{HA}+\mathrm{OA}+\mathrm{PCO}, \mathrm{HA}+\mathrm{OA}$, and $\mathrm{OA}+\mathrm{PCO}$ subgroups had a higher T-AOC; the HA+OA+ PCO and HA + PCO subgroups had higher PON1 levels and
PON1 lactonase activities and increased or tended to increase the PON1 192RR genotypic frequencies (for HA+ OA+PCO subgroup: $35.1 \%$ vs $45.0 \%, P=0.015$ and for HA + PCO subgroup: $35.1 \%$ vs $50.0 \%, P=0.065)$; the $\mathrm{HA}+$ $\mathrm{OA}+\mathrm{PCO}$ subgroup had a higher NLA. Patients with OA+ PCO also had lower MDA levels compared with the other three PCOS subgroups, lower T-AOC levels, lower PON1 levels and PON1 lactonase activities, and a lower NLA compared with the $\mathrm{HA}+\mathrm{OA}+\mathrm{PCO}$ subgroup; the levels and lactonase activities of PON1 were lower or tend to be decreased compared with the HA+PCO subgroup $(P<0.062)$.

\section{Effects of PON1 - 108C/T, 192Q/R, and 55L/M genetic variants on the lactonase activity and status of PON1 and oxidative stress parameters}

As given in Table 3 , the PON1 $-108 C \rightarrow T$ variants decreased PON1 levels and PON1 lactonase activities in a genotype-dependent manner $(C C>C T>T T)$ but did not significantly affect the NLA in patients with PCOS or the control women. The T-AOC was higher in patients with TT genotype than in patients with $C C$ genotype.

The PON1 lactonase activities and NLA were significantly increased in patients with $R R$ genotype compared with patients with the $Q Q$ or $Q R$ genotype. In the control women, PON1 $192 Q \rightarrow R$ variants increased the PON1

Table 2 Lactonase activity, level, NLA, and genotypic frequencies of PON1 and markers of oxidative stress in different PCOS phenotypes and control women. Values are as means \pm s.D. Comparisons of the lactonase activity, level, and NLA of PON1 and markers of oxidative stress were corrected for differences in age and BMI between the two groups; the genotypic distributions of PON1 were compared by $\chi^{2}$ tests.

\begin{tabular}{|c|c|c|c|c|c|}
\hline & \multirow[b]{2}{*}{ Controls $(n=441)$} & \multicolumn{4}{|c|}{ PCOS } \\
\hline & & $\mathrm{HA}+\mathrm{OA}+\mathrm{PCO}(n=191)$ & $\mathrm{HA}+\mathrm{OA}(n=93)$ & $\mathrm{HA}+\mathrm{PCO}(n=26)$ & $\mathrm{OA}+\mathrm{PCO}(n=145)$ \\
\hline Age (years) & $28.11 \pm 4.08$ & $24.85 \pm 3.55^{*}$ & $24.71 \pm 3.83^{*}$ & $26.03 \pm 4.45^{*}$ & $25.61 \pm 3.80 *$ \\
\hline BMI $\left(\mathrm{kg} / \mathrm{m}^{2}\right)$ & $21.01 \pm 2.74$ & $22.70 \pm 3.86 *$ & $23.01 \pm 4.70 *$ & $22.50 \pm 4.39$ & $23.84 \pm 4.58 *$ \\
\hline MDA (nmol/ml) & $3.60 \pm 1.20$ & $4.30 \pm 1.64 *$ & $4.55 \pm 1.76 *$ & $4.59 \pm 1.55^{*}$ & $3.96 \pm 1.41 *,+, \neq, \S$ \\
\hline T-AOC (U/ml per min) & $14.97 \pm 2.80$ & $16.73 \pm 3.16^{*}$ & $16.09 \pm 3.21 *$ & $15.40 \pm 2.84$ & $16.01 \pm 3.22^{*, \dagger}$ \\
\hline PON1 lactonase activity (U/ml) & $9.43 \pm 1.62$ & $9.93 \pm 1.65 *$ & $9.59 \pm 1.60^{\dagger}$ & $10.27 \pm 2.27 *$ & $9.47 \pm 1.68^{\dagger}$ \\
\hline PON1 level (mU/ml) & $44.23 \pm 6.43$ & $46.01 \pm 6.51$ * & $44.89 \pm 6.47$ & $48.38 \pm 9.24^{*, \neq}$ & $44.42 \pm 6.38^{\dagger, \S}$ \\
\hline NLA & $213.01 \pm 16.79$ & $215.57 \pm 16.37 *$ & $213.70 \pm 18.61$ & $211.14 \pm 19.45$ & $212.61 \pm 16.69^{\dagger}$ \\
\hline \multicolumn{6}{|l|}{ PON1 genotypes, \% (n) } \\
\hline$-108 \mathrm{CC}$ & $30.4(134)$ & $29.8(57)$ & $28.0(26)$ & $42.3(11)$ & $26.2(38)$ \\
\hline$C T$ & $52.8(233)$ & $47.6(91)$ & $59.1(55)$ & $38.5(10)$ & $50.3(73)$ \\
\hline$T T$ & $16.8(74)$ & $22.5(43)$ & $12.9(12)$ & $19.2(5)$ & $23.4(34)$ \\
\hline 192QQ & $14.5(64)$ & $7.9(15) *$ & $11.8(11)$ & $23.1(6)$ & $12.4(18)$ \\
\hline$Q R$ & $50.3(222)$ & $47.1(90)$ & $47.3(44)$ & $26.9(7)$ & $43.4(63)$ \\
\hline$R R$ & 35.1 (155) & $45.0(86)$ & $40.9(38)$ & 50.0 (13) & 44.1 (64) \\
\hline $55 L L$ & $92.5(408)$ & 93.7 (179) & $94.6(88)$ & $100(26)$ & 93.1 (135) \\
\hline$L M$ & 7.5 (33) & $6.3(12)$ & $5.4(5)$ & $0(0)$ & $6.9(10)$ \\
\hline
\end{tabular}

HA, hyperandrogenism; MDA, malondialdehyde; NLA, normalized lactonase activity; OA, oligo- and/or anovulation; PCO, polycystic ovaries; PON1, paraoxonase 1 ; PCOS, polycystic ovarian syndrome; T-AOC, total antioxidant capacity. ${ }^{*} P<0.05$ compared with the controls. ${ }^{\dagger} P<0.05$ compared with the $\mathrm{HA}+\mathrm{OA}+\mathrm{PCO}$ subgroup. ${ }^{\ddagger} P<0.05$ compared with the HA+OA subgroup. ${ }^{\S} P<0.05$ compared with the HA+PCO subgroup. 


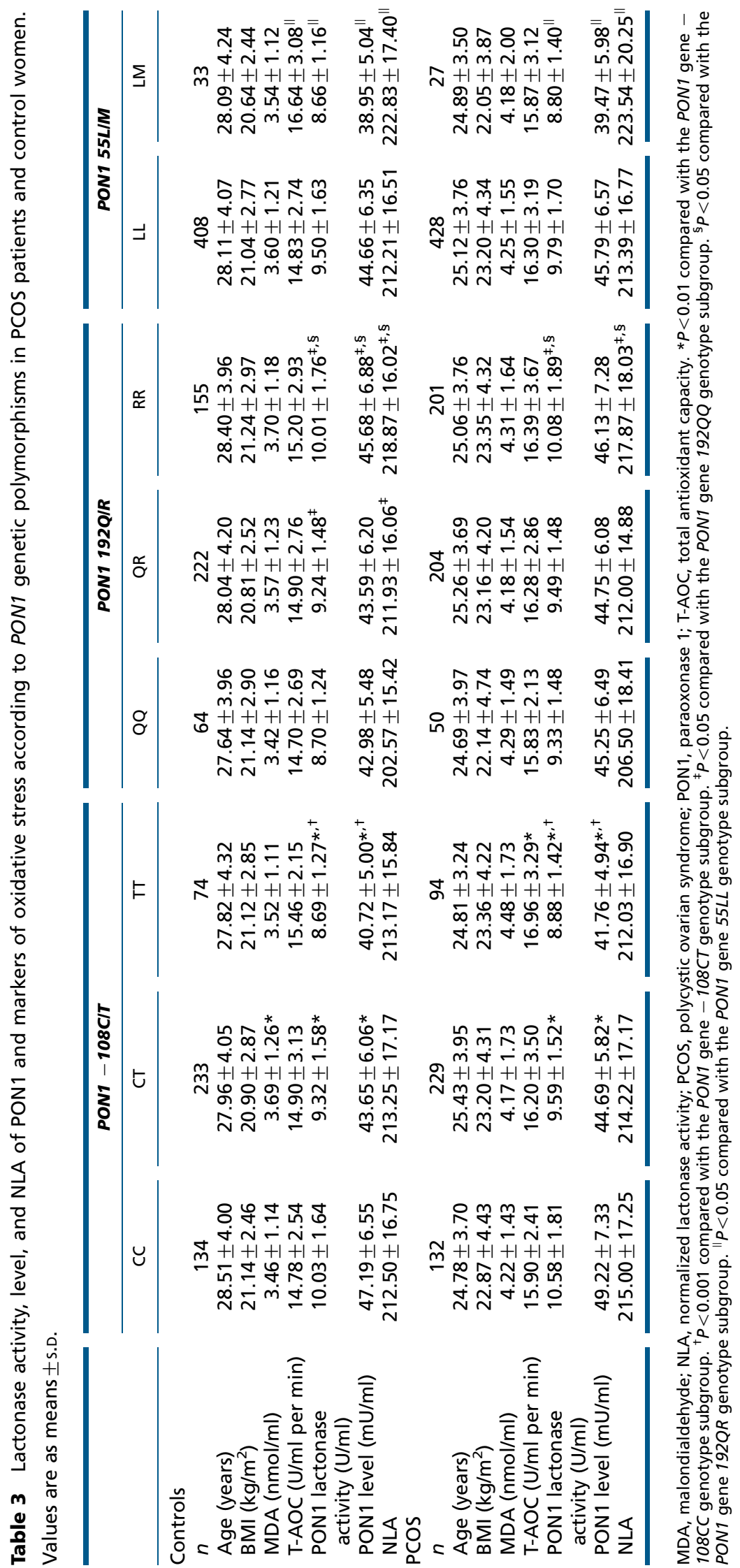


lactonase activities and NLA in a genotype-dependent manner $(R R>Q R>Q Q)$; the PON1 levels were also increased in the $R R$ genotype compared with the controls with the $Q Q$ or $Q R$ genotype.

The PON1 $55 L \rightarrow M$ variants significantly decreased PON1 levels and PON1 lactonase activities and increased the NLA in the PCOS patients and the control women.

\section{Relationship of the lactonase activity and status of PON1 with PON1 genetic variants, clinical, hormonal, metabolic, and oxidative stress parameters in subjects}

A bivariate analysis showed that the PON1 lactonase activities positively correlated with the PON1 levels $(r=0.898, P<0.001)$.

The multivariate stepwise regression analysis showed that the PON1 $-108 \mathrm{C} / \mathrm{T}, 192 \mathrm{Q} / \mathrm{R}$, and $55 \mathrm{~L} / \mathrm{M}$ genetic variants and the apoA1, MDA, and LDL-C levels were significant predictors of the PON1 lactonase activities; the PON1 $-108 C / T, 192 \mathrm{Q} / \mathrm{R}$, and 55L/M genetic variants; the apoA1 and MDA levels; and PCOS status were significant predictors of the PON1 levels; the PON1 - 108C/T, $192 \mathrm{Q} / \mathrm{R}$, and $55 \mathrm{~L} / \mathrm{M}$ genetic variants; SBP; and the apoA1, LDL-C, TG, and MDA levels were significant predictors of the NLA (Table 4).

\section{Discussion}

In this study, we found that the lactonase activities and concentrations of PON1 as well as the PON1 192RR genotypic frequencies were increased in PCOS patients with $\mathrm{HA}+\mathrm{OA}+\mathrm{PCO}$ and $\mathrm{HA}+\mathrm{PCO}$, and the NLA was increased in patients with $\mathrm{HA}+\mathrm{OA}+\mathrm{PCO}$ among the four PCOS phenotypes (based on the Rotterdam criteria), suggesting that a compensatory stimulation of PON1 lactonase activities and some genetic components may

Table 4 Association of important independent variables with lactonase activity, level, and NLA of PON1 by multivariate regression analysis in subjects.

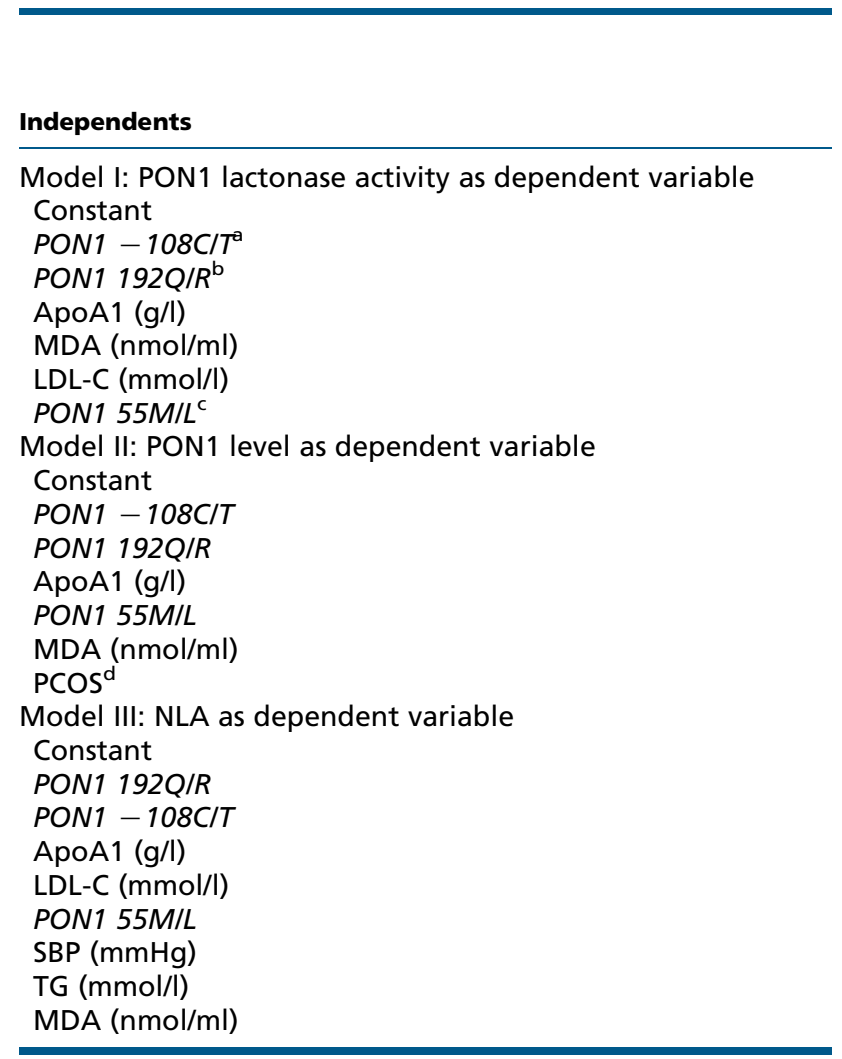

\begin{tabular}{c}
$\begin{array}{c}\text { Unstandardicicie } \\
\text { coefficie }\end{array}$ \\
\hline$B$ \\
\hline \\
\hline 3.052 \\
1.444 \\
1.083 \\
2.660 \\
0.215 \\
0.374 \\
0.974 \\
\\
-3.564 \\
5.507 \\
2.791 \\
10.202 \\
6.816 \\
0.716 \\
1.808 \\
\\
133.904 \\
9.046 \\
5.587 \\
16.826 \\
3.514 \\
-10.341 \\
0.239 \\
2.025 \\
1.219 \\
\hline
\end{tabular}

\begin{tabular}{|c|c|c|}
\hline $\begin{array}{l}\text { Standardized } \\
\text { coefficients }\end{array}$ & & \\
\hline \multirow[t]{2}{*}{$\beta$} & $t$ & $\boldsymbol{P}$ \\
\hline & -3.133 & 0.002 \\
\hline 0.595 & 12.413 & $<0.001$ \\
\hline 0.421 & 8.688 & $<0.001$ \\
\hline 0.283 & 6.403 & $<0.001$ \\
\hline 0.198 & 4.437 & $<0.001$ \\
\hline 0.154 & 3.534 & $<0.001$ \\
\hline \multirow[t]{2}{*}{0.132} & 2.991 & 0.003 \\
\hline & -0.942 & 0.347 \\
\hline 0.584 & 12.007 & $<0.001$ \\
\hline 0.279 & 5.646 & $<0.001$ \\
\hline 0.279 & 6.210 & $<0.001$ \\
\hline 0.237 & 5.313 & $<0.001$ \\
\hline 0.170 & 3.713 & $<0.001$ \\
\hline \multirow[t]{2}{*}{0.105} & 2.343 & 0.020 \\
\hline & 8.177 & $<0.001$ \\
\hline 0.350 & 5.938 & $<0.001$ \\
\hline 0.229 & 3.935 & $<0.001$ \\
\hline 0.178 & 3.266 & 0.001 \\
\hline 0.145 & 2.677 & 0.008 \\
\hline-0.139 & -2.574 & 0.011 \\
\hline 0.138 & 2.561 & 0.011 \\
\hline 0.115 & 2.094 & 0.037 \\
\hline 0.112 & 2.048 & 0.041 \\
\hline
\end{tabular}

ApoA1, apolipoprotein A1; LDL-C, LDL-cholesterol; MDA, malondialdehyde; NLA, normalized lactonase activity; PCOS, polycystic ovarian syndrome; PON1, paraoxonase 1; SBP, systolic blood pressure; TG, triglycerides.

aPON1 $-108 \mathrm{C} / \mathrm{T}(\mathrm{TT}=1, \mathrm{CT}=2$, and $\mathrm{CC}=3)$.

${ }^{\mathrm{b}} \mathrm{PON} 1192 \mathrm{Q} / \mathrm{R}(\mathrm{QQ}=1, \mathrm{QR}=2$, and $\mathrm{RR}=3)$.

${ }^{C} P O N 155 \mathrm{M} / \mathrm{L}(\mathrm{ML}=1$ and $\mathrm{LL}=2)$.

${ }^{\mathrm{d}} \mathrm{PCOS}$ (control $=0$ and $\mathrm{PCOS}=1$ ). 
be present in these patients. We also showed that the PON1 $-108 \mathrm{C} / \mathrm{T}, 192 \mathrm{Q} / \mathrm{R}$, and 55L/M genetic polymorphisms, oxidative stress, serum apoA1 and lipid levels, and PCOS status might influence the lactonase activities and status of PON1.

This study showed that the MDA levels, PON1 lactonase activities, and PON1 levels were higher in patients with PCOS than in control women, and the MDA level was one of the significant predictors of the PON1 lactonase activities and PON1 levels in the multivariate regression models, suggesting that oxidative stress and the lactonase activities or concentrations of PON1 might be closely linked in these patients. Studies have shown that PON1 inhibits LDL oxidation (38) and stimulates cholesterol efflux from macrophages (39). Impairing the lactonase activity of PON1 via mutations of the catalytic histidine dyad (H115Q and H134Q) reduces the ability of PON1 to prevent LDL oxidation and stimulate macrophage cholesterol efflux, indicating that the anti-atherogenic functions of PON1 may be mediated by its lactonase activity $(23,40)$. PON1 evidently plays an antioxidant role via hydrolyzing lipid peroxides by means of its lactonase activity $(13,18,19)$. PCOS is associated with increased oxidative stress (5) and systemic inflammation (6). Our previous study showed that the increased MDA levels were correlated with elevated TT levels in PCOS patients (41). Gonzalez et al. (42) reported that hyperandrogenemia activated and sensitized leukocytes to glucose and increased leukocytic NADPH oxidase $P 47$ (phox) subunit gene expression and reactive oxygen species generation in normal-weight PCOS women. The increased oxidative stress was reportedly associated with insulin resistance (43), systemic inflammation, endothelial dysfunction $(44,45)$, stimulated proliferation, testosterone production of theca cells $(45,46)$, and increased hepatic PON1 protein expression $(47,48)$. These findings support our results that the elevated lactonase activities and levels of PON1 might be a compensation for increased oxidative stress and inflammation in PCOS patients. Conversely, PON1 is sensitive to the oxidative stress status which can lead to enzyme inactivation and consumption (49), which may explain the decreased serum PON1 activity and/or levels that are associated with increased PON1 protein expression in some disease statuses $(47,48)$. In brief, PON1 plays an important role in preventing oxidative stress and controlling inflammation, and the absolute or relative lack of PON1 lactonase activity may contribute to PCOS pathology.
This study also showed that apoA1 levels were significant predictors of PON1 lactonase activities, PON1 levels, and the NLA; the PON1 lactonase activities positively correlated with PON1 levels $(r=0.898)$, suggesting that the PON1 protein concentrations and apoA1 levels are important factors that influence the PON1 lactonase activities. The PON1 DEPCyMCase activities have been shown to be a good marker of PON1 protein levels because they are not influenced by the degree of catalytic stimulation by HDL and can provide information similar to direct PON1 quantification by ELISA (21). The PON1 AREase activity is also considered as the classical surrogate marker of PON1 concentration, but it undergoes an approximately twofold higher stimulation upon HDL binding; thus, phenylacetate may not be a suitable substrate for assessing PON1 concentration (22). ApoA1HDL or apoE-HDL binding to PON1 can significantly increase the stability of PON1 and stimulate the lactonase activities of PON1 $(50,51)$, while the dissociation of PON1 from HDL to the lipoprotein-deficient serum fraction is accompanied by a loss of PON1 lactonase activities and anti-atherogenic properties (52). In addition, we found that a high stimulation of PON1 lactonase activities due to increased NLA is associated with the $\mathrm{HA}+\mathrm{OA}+\mathrm{PCO}$ phenotype, and the significant predictors of NLA were TG, LDL-C, and SBP. Consistent with our findings, NLA was also increased in patients with coronary artery disease (CAD) (24). Recent studies have shown that HDLs from CAD patients enriched in PON1 (53) and proatherogenic small and density LDLs tend to be associated with increased PON1 activity (54). Based on these findings, we speculate that PCOS-related changes in the HDL composition and presence of proatherogenic lipidemia could, at least partly, be associated with a compensatory stimulation of PON1 lactonase activity.

Our study showed that the PON1 $-108 C / T, 192 \mathrm{Q} / R$, and $55 \mathrm{~L} / \mathrm{M}$ genetic variants were important predictors of PON1 lactonase activities, PON1 levels, and the NLA in the multivariate regression analysis; the PON1 $-108 \mathrm{C} \rightarrow T$ variants genotype-dependently decrease the serum PON1 concentrations and thus decrease the PON1 lactonase activities, but these variants did not significantly affect the degree of catalytic stimulation by HDL in the patients and the controls; the PON1 $192 Q \rightarrow R$ variants genotypedependently increase the PON1 lactonase activities and the degree of catalytic stimulation by HDL in the control women; the serum lactonase activities and concentrations of PON1 are higher in subjects with PON1 55LL genotype than in subjects with the 55LM genotype. Consistent with our results, the PON1 genetic polymorphisms have been 
shown to regulate the PON1 status on HDL in circulation and account for more than $60 \%$ of the interindividual variation in enzyme concentration and activity $(12,13,34)$. Studies have found that the promoter region $-108 \mathrm{C} \rightarrow T$ variants decrease the PON1 expression and protein level, the PON1 Q192R polymorphism itself does not affect PON1 protein concentrations but greatly influences the PON1 activities, and the PON1 55L/M polymorphism influences both the PON1 concentrations and activities $(12,55)$. The PON1 mRNA and protein levels are significantly higher in $55 \mathrm{~L}$ allele carriers (12) and the POase and lactonase activities were higher in the $55 \mathrm{LL}$ homozygotes (56). In addition, unlike most other studies, we find that the PON1 concentrations were higher in the controls harboring the PON1 192RR genotype than in controls harboring the $Q Q$ or $Q R$ genotype. The increases may be due to the PON1 $-108 \mathrm{C}$ allele, which increases PON1 expression and may partly compensate for the PON1 concentrations afforded by the $\mathrm{R}$ isoform because the PON1 192R allele has been reported to be in linkage disequilibrium with the PON1 $-108 \mathrm{C}$ allele $(34,56)$. Similarly, the effects of $P O N 155 \mathrm{~L} / \mathrm{M}$ polymorphism on the PON1 concentrations and activities might be largely due to the linkage disequilibrium among the $55 L, 192 R$, and $-108 \mathrm{C}$ alleles and between $55 \mathrm{M}$ and $192 \mathrm{Q}(34,56)$.

In addition, we showed that the lactonase activities and levels of PON1 and the 192RR genotypic frequencies were significantly higher or tended to be increased in PCOS patients with $\mathrm{HA}+\mathrm{OA}+\mathrm{PCO}$ or $\mathrm{HA}+\mathrm{PCO}$ than in the controls, suggesting that the increased 192RR genotypic frequencies may contribute to the increased lactonase activities and levels of PON1 in these patients. On the other hand, we also found that unlike the control 192QR or $R R$ genotypic subgroups, the increase in PON1 lactonase activities and NLA is of limited in PCOS patients with $192 Q R$ or $R R$ genotype (Table 3 ). Our previous study showed that the PCOS patients with $Q R$ or $R R$ genotype had significantly higher or tend to increase WC, WHR, fasting insulin and TG levels, and HOMA-IR compared with patients with $Q Q$ genotype, while such relationships were not detected in the control women (34), suggesting that abdominal obesity and insulin resistance, which is often associated with the decreased apoA1 levels and the increased plasma glucose levels, may impair PON1 lactonase activities by the glycation of HDL and the reduced stimulation of apoA1 on PON1 (13). In addition, we found that the PON1 concentrations were lowest and the degree of catalytic stimulation by HDL was highest in the subjects harboring the 55LM genotype. However, our previous study showed that the degree of obesity and insulin resistance was similar between the PCOS patients harboring the 55LM genotype and the patients harboring the $L M$ genotype (34). Thus, the association of this high stimulation by HDL with the amino acid change in the PON1 55 site remains to be determined.

Notably, the allele frequencies for PON1 polymorphisms differ among ethnic groups. The frequency of the $192 R$ allele among Chinese subjects in the current study $(60 \%)$ is higher compared with other populations, such as Greek (9.5\%), Caucasians (24-31\%), Asian Indian (31\%), and Hispanic Americans (42-46\%), and similar to Korean $(60 \%)$ and Japanese $(59-66 \%)(57,58)$. The frequency of the $55 \mathrm{M}$ allele was $4 \%$ in this study carried out in the Chinese population. It was shown to be higher in Caucasians (26-38\%), and similar to Korean (3\%), but slightly higher in Japanese (9-10\%) (58). The frequency of the $-108 T$ allele among Chinese subjects in this study (43\%) was lower compared with Caucasians (50-54\%) (59), and similar to Greek (43.5\%) (57), but higher compared with African Americans (15.5\%) and Hispanics (35\%) (58). Interestingly, the PON1 192RR genotype, but not - 108TT genotype, was associated with PCOS in our previous studies $(34,37)$. However, the PON1 - 108TT and 192RR genotypes are more frequently encountered in Greek PCOS than in non-PCOS women (57). This inconsistency may be in part attributed to different genetic background between the two populations. In addition, environmental factors such as smoking, a high-fat diet, and consumption of antioxidants may also affect PON1 status on HDL in circulation or PON1 expression (60). Therefore, it is possible that the relationships between PON1 genetic polymorphism and PON1 lactonase activity, PON1 level, or disease may be different among different populations.

This study has several limitations. First, we only measured the TT levels, which may be a less sensitive marker for HA than the free testosterone levels. Second, the presence of tubal factor may have biased the control group in this study. Finally, the sample size of the HA+ PCO phenotype was relatively small, and a larger number of subjects is needed to properly evaluate their characteristics.

In summary, the increased serum lactonase activities and concentrations of PON1 and MDA levels in the PCOS patients with $\mathrm{HA}+\mathrm{OA}+\mathrm{PCO}$ and $\mathrm{HA}+\mathrm{PCO}$, along with the observed positive correlation between these parameters, suggests that increased oxidative stress may partly be related to a compensatory stimulation of PON1 lactonase activities in these patients with PCOS. In addition, the PON1 $-108 \mathrm{C} / \mathrm{T}, 192 \mathrm{Q} / \mathrm{R}$, and $55 \mathrm{~L} / \mathrm{M}$ genetic 
polymorphisms also significantly affect the lactonase activities and status of PON1.

\section{Supplementary data}

This is linked to the online version of the paper at http://dx.doi.org/10.1530/ EJE-14-0863.

\section{Declaration of interest}

The authors declare that there is no conflict of interest that could be perceived as prejudicing the impartiality of the research reported.

\section{Funding}

This work was supported by the Chinese National Natural Science Foundation (grant numbers 81070463 and 81370681) and the Program for Changjiang Scholars and Innovative Research Team in University, Ministry of Education (grant number IRT0935).

\section{Author contribution statement}

P Fan designed, performed the study, analyzed the data, and wrote the paper. $Y$ Zhang collected samples, did experiments, and analyzed the data. $J \mathrm{He}, \mathrm{K} X \mathrm{U}$, and L Cheng synthesized TBBL and DEPCyMC. J Zhang, Y Wang, and $\mathrm{F}$ Zhang collected samples and helped with the experiments. $\mathrm{H}$ Liu was responsible for patients screening. $\mathrm{H}$ Bai revised the paper. All authors discussed the results and commented on the manuscript.

\section{Acknowledgements}

The authors thank all subjects who donated blood samples for this study. They are thankful to You Li, Dehua Wan, Qi Song, Lanhong Su, and Wenlu Yang for the work performed to support this study.

\section{References}

1 The Rotterdam ESHRE/ASRM-Sponsored PCOS Consensus Workshop Group. Revised 2003 consensus on diagnostic criteria and long-term health risks related to polycystic ovary syndrome. Fertility and Sterility 200481 19-25. (doi:10.1016/j.fertnstert.2003.10.004)

2 Li R, Zhang Q, Yang D, Li S, Lu S, Wu X, Wei Z, Song X, Wang X, Fu S et al. Prevalence of polycystic ovary syndrome in women in China: a large community-based study. Human Reproduction 201328 2562-2569. (doi:10.1093/humrep/det262)

3 March WA, Moore VM, Willson KJ, Phillips DI, Norman RJ \& Davies MJ. The prevalence of polycystic ovary syndrome in a community sample assessed under contrasting diagnostic criteria. Human Reproduction 2010 25 544-551. (doi:10.1093/humrep/dep399)

4 Lim SS, Davies MJ, Norman RJ \& Moran LJ. Overweight, obesity and central obesity in women with polycystic ovary syndrome: a systematic review and meta-analysis. Human Reproduction Update 201218 618-637. (doi:10.1093/humupd/dms030)

5 Murri M, Luque-Ramirez M, Insenser M, Ojeda-Ojeda M \& EscobarMorreale HF. Circulating markers of oxidative stress and polycystic ovary syndrome (PCOS): a systematic review and meta-analysis. Human Reproduction Update 201319 268-288. (doi:10.1093/humupd/ dms059)
6 Repaci A, Gambineri A \& Pasquali R. The role of low-grade inflammation in the polycystic ovary syndrome. Molecular and Cellular Endocrinology 2011335 30-41. (doi:10.1016/j.mce.2010.08.002)

7 Moran LJ, Misso ML, Wild RA \& Norman RJ. Impaired glucose tolerance, type 2 diabetes and metabolic syndrome in polycystic ovary syndrome: a systematic review and meta-analysis. Human Reproduction Update 201016 347-363. (doi:10.1093/humupd/dmq001)

8 Meyer ML, Malek AM, Wild RA, Korytkowski MT \& Talbott EO. Carotid artery intima-media thickness in polycystic ovary syndrome: a systematic review and meta-analysis. Human Reproduction Update 2012 18 112-126. (doi:10.1093/humupd/dmr046)

9 de Groot PC, Dekkers OM, Romijn JA, Dieben SW \& Helmerhorst FM. PCOS, coronary heart disease, stroke and the influence of obesity: a systematic review and meta-analysis. Human Reproduction Update 2011 17 495-500. (doi:10.1093/humupd/dmr001)

10 Goodarzi MO. Looking for polycystic ovary syndrome genes: rational and best strategy. Seminars in Reproductive Medicine 200826 5-13. (doi:10.1055/s-2007-992919)

11 Escobar-Morreale HF, Luque-Ramirez M \& San Millan JL. The molecular-genetic basis of functional hyperandrogenism and the polycystic ovary syndrome. Endocrine Reviews 200526 251-282. (doi:10.1210/er.2004-0004)

12 Precourt LP, Amre D, Denis MC, Lavoie JC, Delvin E, Seidman E \& Levy E. The three-gene paraoxonase family: physiologic roles, actions and regulation. Atherosclerosis 2011214 20-36. (doi:10.1016/j.atherosclerosis.2010.08.076)

13 Camps J, Marsillach J \& Joven J. The paraoxonases: role in human diseases and methodological difficulties in measurement. Critical Reviews in Clinical Laboratory Sciences 200946 83-106. (doi:10.1080/ 10408360802610878)

14 Perla-Kajan J \& Jakubowski H. Paraoxonase 1 and homocysteine metabolism. Amino Acids 201243 1405-1417. (doi:10.1007/s00726012-1321-z)

15 Aviram M \& Vaya J. Paraoxonase 1 activities, regulation, and interactions with atherosclerotic lesion. Current Opinion in Lipidology 201324 339-344. (doi:10.1097/MOL.0b013e32835ffcfd)

16 Camps J, Garcia-Heredia A, Rull A, Alonso-Villaverde C, Aragones G, Beltran-Debon R, Rodriguez-Gallego E \& Joven J. PPARs in regulation of paraoxonases: control of oxidative stress and inflammation pathways. PPAR Research 20122012 616371. (doi:10.1155/2012/616371)

17 Soran H, Younis NN, Charlton-Menys V \& Durrington P. Variation in paraoxonase-1 activity and atherosclerosis. Current Opinion in Lipidology 200920 265-274. (doi:10.1097/MOL.0b013e32832ec141)

18 Khersonsky O \& Tawfik DS. Structure-reactivity studies of serum paraoxonase PON1 suggest that its native activity is lactonase. Biochemistry 200544 6371-6382. (doi:10.1021/bi047440d)

19 Draganov DI, Teiber JF, Speelman A, Osawa Y, Sunahara R \& La Du BN Human paraoxonases (PON1, PON2, and PON3) are lactonases with overlapping and distinct substrate specificities. Journal of Lipid Research 200546 1239-1247. (doi:10.1194/jlr.M400511-JLR200)

20 Perla-Kajan J \& Jakubowski H. Paraoxonase 1 protects against protein $N$-homocysteinylation in humans. FASEB Journal 201024 931-936. (doi:10.1096/fj.09-144410)

21 Gaidukov L \& Tawfik DS. The development of human sera tests for HDL-bound serum PON1 and its lipolactonase activity. Journal of Lipid Research 200748 1637-1646. (doi:10.1194/jlr.D600045-JLR200)

22 Khersonsky O \& Tawfik DS. Chromogenic and fluorogenic assays for the lactonase activity of serum paraoxonases. Chembiochem: a European Journal of Chemical Biology 20067 49-53. (doi:10.1002/cbic.200500334)

23 Rosenblat M, Gaidukov L, Khersonsky O, Vaya J, Oren R, Tawfik DS \& Aviram M. The catalytic histidine dyad of high density lipoproteinassociated serum paraoxonase-1 (PON1) is essential for PON1-mediated inhibition of low density lipoprotein oxidation and stimulation of macrophage cholesterol efflux. Journal of Biological Chemistry 2006281 7657-7665. (doi:10.1074/jbc.M512595200) 
24 Martinelli N, Girelli D, Olivieri O, Guarini P, Bassi A, Trabetti E, Friso S, Pizzolo F, Bozzini C, Tenuti I et al. Novel serum paraoxonase activity assays are associated with coronary artery disease. Clinical Chemistry and Laboratory Medicine 200947 432-440. (doi:10.1515/CCLM.2009.108)

25 Soyman Z, Noyan V, Tulmac M, Yucel A, Sagsoz N, Bayrak T, Bayrak A \& Cakir E. Serum paraoxonase 1 activity, asymmetric dimethylarginine levels, and brachial artery flow-mediated dilatation in women with polycystic ovary syndrome. Fertility and Sterility 201195 1067-1072. (doi:10.1016/j.fertnstert.2010.12.011)

26 Mohamadin AM, Habib FA \& Elahi TF. Serum paraoxonase 1 activity and oxidant/antioxidant status in Saudi women with polycystic ovary syndrome. Pathophysiology 201017 189-196. (doi:10.1016/j.pathophys.2009.11.004)

27 Fenkci IV, Serteser M, Fenkci S \& Kose S. Paraoxonase levels in women with polycystic ovary syndrome. Journal of Reproductive Medicine 2007 52 879-883.

28 Dursun P, Demirtas E, Bayrak A \& Yarali H. Decreased serum paraoxonase 1 (PON1) activity: an additional risk factor for atherosclerotic heart disease in patients with PCOS? Human Reproduction 2006 21 104-108. (doi:10.1093/humrep/dei284)

29 Torun AN, Vural M, Cece H, Camuzcuoglu H, Toy H \& Aksoy N. Paraoxonase-1 is not affected in polycystic ovary syndrome without metabolic syndrome and insulin resistance, but oxidative stress is altered. Gynecological Endocrinology 201127 988-992. (doi:10.3109/ 09513590.2011.569798)

30 San Millan JL, Alvarez-Blasco F, Luque-Ramirez M, Botella-Carretero JI \& Escobar-Morreale HF. The PON1-108C/T polymorphism, and not the polycystic ovary syndrome, is an important determinant of reduced serum paraoxonase activity in premenopausal women. Human Reproduction 200621 3157-3161. (doi:10.1093/humrep/del300)

31 Bayrak T, Dursun P, Bayrak A, Gultekin M, Kolusari A, Cakir E, Ozyurt M \& Zeyneloglu HB. Paraoxonase lactonase activity (PON-HTLase), asymmetric dimethylarginine (ADMA) and platelet activating factoracetylhydrolase (PAF-AH) activity in non-obese women with PCOS. Gynecological Endocrinology 201228 874-878. (doi:10.3109/09513590. 2012.683068)

32 Liu HW, Zhang F, Fan P, Bai H, Zhang JX \& Wang Y. Effects of apolipoprotein $\mathrm{E}$ genotypes on metabolic profile and oxidative stress in south-west Chinese women with polycystic ovary syndrome. European Journal of Obstetrics, Gynecology, and Reproductive Biology $2013 \mathbf{1 7 0}$ 146-151. (doi:10.1016/j.ejogrb.2013.04.016)

33 Zhang J, Fan P, Liu H, Bai H, Wang Y \& Zhang F. Apolipoprotein A-I and $B$ levels, dyslipidemia and metabolic syndrome in south-west Chinese women with PCOS. Human Reproduction 201227 2484-2493. (doi:10.1093/humrep/des191)

34 Wang Y, Liu H, Fan P, Bai H, Zhang J \& Zhang F. Evidence for association between paraoxonase 1 gene polymorphisms and polycystic ovarian syndrome in southwest Chinese women. European Journal of Endocrinology 2012166 877-885. (doi:10.1530/EJE-11-0986)

35 Fan P, Liu HW, Wang XS, Zhang F, Song Q, Li Q, Wu HM \& Bai H. Identification of the G994T polymorphism in exon 9 of plasma platelet-activating factor acetylhydrolase gene as a risk factor for polycystic ovary syndrome. Human Reproduction 201025 1288-1294. (doi:10.1093/humrep/deq047)

36 Robert Y, Dubrulle F, Gaillandre L, Ardaens Y, Thomas-Desrousseaux P, Lemaitre L \& Dewailly D. Ultrasound assessment of ovarian stroma hypertrophy in hyperandrogenism and ovulation disorders: visual analysis versus computerized quantification. Fertility and Sterility 1995 64 307-312.

37 Zhang F, Liu HW, Fan P, Bai H \& Song Q. The -108 C/T polymorphism in paraoxonase 1 gene in Chinese patients with polycystic ovary syndrome. Sichuan Da Хие Хие Bao. Yi Хие Ban 201142 24-28.

38 Watson AD, Berliner JA, Hama SY, La Du BN, Faull KF, Fogelman AM \& Navab M. Protective effect of high density lipoprotein associated paraoxonase. Inhibition of the biological activity of minimally oxidized low density lipoprotein. Journal of Clinical Investigation 1995 96 2882-2891. (doi:10.1172/JCI118359)

39 Rosenblat M, Vaya J, Shih D \& Aviram M. Paraoxonase 1 (PON1) enhances HDL-mediated macrophage cholesterol efflux via the ABCA1 transporter in association with increased HDL binding to the cells: a possible role for lysophosphatidylcholine. Atherosclerosis 2005179 69-77. (doi:10.1016/j.atherosclerosis.2004.10.028)

40 Khersonsky O \& Tawfik DS. The histidine 115-histidine 134 dyad mediates the lactonase activity of mammalian serum paraoxonases. Journal of Biological Chemistry 2006281 7649-7656. (doi:10.1074/jbc.M512594200)

41 Fan P, Liu H, Wang Y, Zhang F \& Bai H. Apolipoprotein E-containing HDL-associated platelet-activating factor acetylhydrolase activities and malondialdehyde concentrations in patients with PCOS. Reproductive Biomedicine Online 201224 197-205. (doi:10.1016/j.rbmo.2011.10.010)

42 Gonzalez F, Sia CL, Shepard MK, Rote NS \& Minium J. Hyperglycemiainduced oxidative stress is independent of excess abdominal adiposity in normal-weight women with polycystic ovary syndrome. Human Reproduction 201227 3560-3568. (doi:10.1093/humrep/des320)

43 Evans JL, Maddux BA \& Goldfine ID. The molecular basis for oxidative stress-induced insulin resistance. Antioxidants \& Redox Signaling 20057 1040-1052. (doi:10.1089/ars.2005.7.1040)

44 Navab M, Ananthramaiah GM, Reddy ST, Van Lenten BJ, Ansell BJ, Fonarow GC, Vahabzadeh K, Hama S, Hough G, Kamranpour N et al. The oxidation hypothesis of atherogenesis: the role of oxidized phospholipids and HDL. Journal of Lipid Research 200445 993-1007. (doi:10.1194/jlr.R400001-JLR200)

45 Kodaman PH \& Duleba AJ. HMG-CoA reductase inhibitors: do they have potential in the treatment of polycystic ovary syndrome? Drugs 200868 1771-1785. (doi:10.2165/00003495-200868130-00001)

46 Duleba AJ, Foyouzi N, Karaca M, Pehlivan T, Kwintkiewicz J \& Behrman HR. Proliferation of ovarian theca-interstitial cells is modulated by antioxidants and oxidative stress. Human Reproduction 200419 1519-1524. (doi:10.1093/humrep/deh299)

47 Martinelli N, Garcia-Heredia A, Roca H, Aranda N, Arija V, Mackness B, Mackness M, Busti F, Aragones G, Pedro-Botet J et al. Paraoxonase-1 status in patients with hereditary hemochromatosis. Journal of Lipid Research 201354 1484-1492. (doi:10.1194/jlr.P028977)

48 Ferre N, Marsillach J, Camps J, Mackness B, Mackness M, Riu F, Coll B, Tous M \& Joven J. Paraoxonase- 1 is associated with oxidative stress, fibrosis and FAS expression in chronic liver diseases. Journal of Hepatology 200645 51-59. (doi:10.1016/j.jhep.2005.12.018)

49 Aviram M, Rosenblat M, Billecke S, Erogul J, Sorenson R, Bisgaier CL, Newton RS \& La Du B. Human serum paraoxonase (PON 1) is inactivated by oxidized low density lipoprotein and preserved by antioxidants. Free Radical Biology \& Medicine 199926 892-904. (doi:10.1016/S0891-5849(98)00272-X)

50 James RW \& Deakin SP. The contribution of high density lipoprotein apolipoproteins and derivatives to serum paraoxonase-1 activity and function. Advances in Experimental Medicine and Biology 2010660 173-181. (doi:10.1007/978-1-60761-350-3_16)

51 Gaidukov L, Viji RI, Yacobson S, Rosenblat M, Aviram M \& Tawfik DS. ApoE induces serum paraoxonase PON1 activity and stability similar to ApoA-I. Biochemistry 201049 532-538. (doi:10.1021/bi9013227)

52 Rosenblat M, Karry R \& Aviram M. Paraoxonase 1 (PON1) is a more potent antioxidant and stimulant of macrophage cholesterol efflux, when present in HDL than in lipoprotein-deficient serum: relevance to diabetes. Atherosclerosis 2006187 74-81. (doi:10.1016/j.atherosclerosis.2005.08.026)

53 Vaisar T, Pennathur S, Green PS, Gharib SA, Hoofnagle AN, Cheung MC, Byun J, Vuletic S, Kassim S, Singh P et al. Shotgun proteomics implicates protease inhibition and complement activation in the antiinflammatory properties of HDL. Journal of Clinical Investigation 2007117 746-756. (doi:10.1172/JCI26206)

54 Vekic J, Kotur-Stevuljevic J, Jelic-Ivanovic Z, Spasic S, SpasojevicKalimanovska V, Topic A, Zeljkovic A, Stefanovic A \& Zunic G. Association of oxidative stress and PON1 with LDL and HDL particle 
size in middle-aged subjects. European Journal of Clinical Investigation 200737 715-723. (doi:10.1111/j.1365-2362.2007.01849.x)

55 Leviev I \& James RW. Promoter polymorphisms of human paraoxonase PON1 gene and serum paraoxonase activities and concentrations. Arteriosclerosis, Thrombosis, and Vascular Biology 200020 516-521. (doi:10.1161/01.ATV.20.2.516)

56 Rainwater DL, Rutherford S, Dyer TD, Rainwater ED, Cole SA, Vandeberg JL, Almasy L, Blangero J, Maccluer JW \& Mahaney MC. Determinants of variation in human serum paraoxonase activity. Heredity 2009102 147-154. (doi:10.1038/hdy.2008.110)

57 Paltoglou G, Tavernarakis G, Christopoulos P, Vlassi M, Gazouli M, Deligeoroglou E, Creatsas G \& Mastorakos G. PON1-108 TT, PON1 - 192 RR genotypes are more frequently encountered in Greek PCOS than non-PCOS women, and are associated with hyperandrogenaemia. Clinical Endocrinology 201379 259-266. (doi:10.1111/cen.12139)

58 Ginsberg G, Neafsey P, Hattis D, Guyton KZ, Johns DO \& Sonawane B. Genetic polymorphism in paraoxonase 1 (PON1): population distribution of PON1 activity. Journal of Toxicology and Environmental Health. Part B, Critical Reviews 200912 473-507. (doi:10.1080/ 10937400903158409)

59 Brophy VH, Jampsa RL, Clendenning JB, McKinstry LA, Jarvik GP \& Furlong CE. Effects of $5^{\prime}$ regulatory-region polymorphisms on paraoxonase-gene (PON1) expression. American Journal of Human Genetics 200168 1428-1436. (doi:10.1086/320600)

60 Camps J, Marsillach J \& Joven J. Pharmacological and lifestyle factors modulating serum paraoxonase-1 activity. Mini Reviews in Medicinal Chemistry 20099 911-920. (doi:10.2174/138955709788681591)

Received 10 October 2014

Revised version received 12 December 2014

Accepted 9 January 2015 